\title{
HUMANIZAÇÃO DA EQUIPE DE ENFERMAGEM NO CONTATO COM A CRIANÇA E A FAMÍLIA ATRAVÉS DO LÚDICO: UM RELATO DE EXPERIÊNCIA
}

\author{
Wezila Gonçalves do NASCIMENTO ${ }^{1}$ \\ Geane SILVA ${ }^{2}$ \\ Jéssica Mayara da Silva OLIVEIRA ${ }^{3}$ \\ Marina Gabriela Medeiros de MOURA ${ }^{4}$ \\ Rosifrance Vidal de Oliveira SANTOS ${ }^{5}$
}

\begin{abstract}
${ }^{1}$ Docente do curso de Bacharelado Enfermagem Faculdade Mauricio de Nassau-CG wezila@ hotmail.com
${ }^{2}$ Enfermeira Residente em Saúde da Família e Comunidade RSFC-JP/FCM silva.geane@ hotmail.com

${ }^{3}$ Discente do curso de Bacharelado em Enfermagem UFCG-CUITÉ jessica_picui@ hotmail.com

${ }^{4}$ Discente do curso de Bacharelado em Enfermagem UFCG-CUITÉ,gabi.iimoura@ hotmail.com

5 orientadora. Professora do Curso de Bacharelado Enfermagem UFCG-CAMPUS CUITÉ. Paraíba. Mestranda em Unidade de Terapia Intensiva rosiv@oi.com.br
\end{abstract}

Recebido em: 24/06/2015 - Aprovado em: 10/01/2016 - Disponibilizado em: 30/07/2016

\begin{abstract}
RESUMO
Objetivo: o presente trabalho tem como objetivo abordar a importância da humanização na pediatria, baseado em referências já publicadas anteriormente. Método: trata-se de um estudo descritivo, tipo relato de experiência, desenvolvido por acadêmicas do Curso de Bacharelado em Enfermagem da Universidade Federal de Campina Grande. Resultados: identificou-se que o ato de brincar tem repercussões na criança, enfermeira e hospital. O brincar ajuda-a na compreensão do que esta ocorrendo, diminui tensões, ansiedade e frustração. Promove satisfação, diversão e espontaneidade. Para a enfermeira é um instrumento de intervenção e uma forma de comunicação, possibilitando detectar a singularidade de cada criança. Quanto ao hospital, altera a visão corrente de que é apenas espaço de dor e sofrimento. Conclusão: destarte percebe-se que a brincadeira de fato ameniza os traumas da internação, portanto deve ser enquadrada não como uma atividade de tempo livre, mas como parte do tratamento, diminuindo assim, o tempo de internação da criança. Descritores: Enfermagem; Brincar; Lúdico; Humanização.
\end{abstract}

Palavras-chave: Enfermaria .Jogo. lúdico. Humanização. Família.

\section{HUMANIZATION NURSING TEAM IN CONTACT WITH THE CHILD AND FAMILY THROUGH} PLAYFUL: AN EXPERIENCE REPORT

\begin{abstract}
Objective: this study aims to address the importance of humanization in pediatrics, based on previously published results. Method: this is a descriptive study, brand experience report, developed by academics from the Bachelor of Nursing, Federal University of Campina Grande. Results: we identified that the act of playing has repercussions on the child, nurse and hospital. The play helps in the understanding of what is occurring, reduces stress, anxiety and frustration. Promotes satisfaction, fun and spontaneity. The nurse is an instrument of intervention and a form of communication, enabling detect the uniqueness of each child. As for the hospital, changes the current view that space is only pain and suffering. Conclusion: thus it can be seen that the joke actually lessens the trauma of hospitalization and therefore should not be framed as a spare time activity, but as part of treatment, thereby reducing the length of hospitalization of the child.
\end{abstract}

Keywords: Nursing, Play, Playful, Humanization.Family 


\section{INTRODUÇÃO}

O presente artigo trata de um relato de experiência do Estágio Supervisionado II, realizado na clínica pediátrica do Hospital Universitário Alcides Carneiro, na cidade de Campina Grande, Paraíba.

As atividades realizadas foram de planejamento e intervenções coerentes com referenciais teóricos e com as características das crianças e do ambiente. As estratégias utilizadas baseavam-se principalmente na busca de ganhar a confiança da criança, a fim de procurar diminuir os paradigmas estressantes relativos aos profissionais de enfermagem; bem como na conversa, escuta e atenção aos acompanhantes. Neste contexto, buscou-se trazer uma abordagem baseada no atendimento holístico e humanizado.

O processo de Humanização nas instituições de saúde surge na atualidade para que se possa repensar as práticas cotidianas de trabalho, reformulando o atendimento que se vem prestando aos usuários desses serviços. Nesse cenário, não é suficiente o hospital adquirir modernos equipamentos, dispor de estrutura moderna apropriada aos cuidados de saúde, se não estiver voltado para a satisfação das necessidades dos usuários e os trabalhadores que os atendem. ${ }^{1}$

A hospitalização é uma situação delicada e estressante na vida de qualquer ser humano, tendo em vista que implica, além dos sofrimentos ocasionados pela doença, mudança importante na rotina e afastamento do conforto oferecido pelo lar. No que tange o universo infantil, a internação hospitalar traduz-se em experiência bastante difícil para o pequeno paciente, gerando ansiedade pela exposição a um ambiente estressante, e onde o apoio para o enfrentamento destes sentimentos é bastante restrito, de tal forma que, uma das únicas fontes de segurança é representada pela presença dos pais. ${ }^{2}$

É importante destacar também que a atmosfera de tensão e insegurança gerada pelo ambiente hospitalar à criança e aos acompanhantes, também acaba acarretando outras situações desagradáveis: novos horários, exames e procedimentos que geram dor, afastamento do ambiente familiar, abandono escolar, falta de estímulos sociais. Essas modificações podem gerar agitação, gritos, choros, retrocesso, regressão, depressão, entre outros, o que acaba por dificultar o processo de recuperação e gerar um estresse generalizado à equipe de saúde $\mathrm{e}$ aos familiares. ${ }^{3}$

No intuito de mudar este cenário, algumas iniciativas vêm sendo implementadas. Com a publicação da Lei $\mathrm{N}^{\circ}$ 8.069, em 1990, regulamentando o Estatuto da Criança e do Adolescente, houve um avanço na humanização da assistência à criança, pois, em seu Artigo 12, explicita que os estabelecimentos de saúde deverão proporcionar condições para a permanência de um dos pais ou responsável, em tempo integral, nos casos de internação de criança ou 
adolescente. Desde então, desenvolver um cuidado em pediatria significa envolver não só a criança, mas abarcar também o seu universo relacional, de modo a considerar criança e família como um só cliente. ${ }^{2}$

\section{OBJETIVOS}

- Desenvolver competências e habilidades, a fim de absorver conhecimentos e buscar avanços, para proporcionar uma melhor assistência à criança e ao acompanhante;

- Abordar a importância da humanização na pediatria, baseado em referências já publicadas anteriormente.

\section{CAMINHO METODOLÓGICO}

Trata-se de um estudo descritivo, tipo relato de experiência, desenvolvido por acadêmicas do Curso de Bacharelado em Enfermagem da Universidade Federal de Campina Grande, localizada na cidade de Cuité - PB durante o Estágio Supervisionado II no Hospital Universitário Alcides Carneiro - HUAC no período de 29 de Outubro de 2013 a 24 de Janeiro de 2014. O intuito deste relato de experiência é abordar a importância da humanização na pediatria, baseado em referências já publicadas anteriormente.

Durante o período de estágio desenvolvemos atividades como: evolução de enfermagem, com o intuito de acompanharmos a evolução das crianças, bem como a eficácia, ou não, do tratamento destas. Também tivemos a oportunidade de aplicar técnicas aprendidas em sala de aula como a realização de passagem de sonda vesical, sonda nasoenteral e nasogástrica; realização de curativos simples e complexos; ações de educação em saúde aos acompanhantes, visando a continuidade do cuidado após a alta; capacitação de mãe adolescente, com o ensino das técnicas apropriadas para o aleitamento e apoio psicológico; administração de medicações orais e parenterais; realização de fliter enema; e realizar ações de caráter burocráticonormativo de competência da enfermagem.

\section{RESULTADOS E DISCUSSÃO}

A hospitalização é uma experiência difícil de ser vivenciada pela criança, devido a necessidade do afastamento familiar, dos amigos, da escola e também por envolver uma rotina desconhecida e dolorosa, onde a presença de um dos pais torna-se um dos poucos recursos de enfrentamento oferecidos a ela. Diante da situação de hospitalização, certas iniciativas de humanização da assistência auxiliam a criança a vivenciar esse processo, entre elas está o uso do Brinquedo Terapêutico (BT). ${ }^{4}$

E quando se trata da hospitalização infantil, esta é vista como um momento marcante na vida da criança, pois durante este processo ela se percebe frágil e incapaz de concretizar suas atividades normalmente, 
modificando seus hábitos diários, como brincar e ir à escola. A imagem de infância é fortemente relacionada ao bem estar, energia e alegria, tornando mais difícil associar a doença e a hospitalização nesta etapa do ciclo vital, tanto por parte da própria criança como de toda sua rede de apoio. ${ }^{5}$

Quando se pensa no cuidado à criança hospitalizada numa visão de atenção integral, não se pode limitar-se apenas às intervenções medicamentosas ou às técnicas de reabilitação. De uma forma geral, a hospitalização acontece em um momento de crise, por meio de complicações da doença crônica ou aguda ou por complicações de outras doenças, independente do motivo, sempre será uma situação diferente para a criança. $^{6}$

A doença e a hospitalização provocam na criança diversas reações que irão depender de vários fatores, entre eles: a separação total ou parcial de familiares expressivos; a idade no período da hospitalização; a condição física e o tipo de cuidado imediato; a qualidade do relacionamento com familiares expressivos antes e durante a hospitalização; o tempo de hospitalização; as experiências já vividas de hospitalização; a quantidade e o tipo de informações de que a criança dispõe; a qualidade e o tipo de apoio que recebe dos familiares expressivos e da equipe de saúde durante a hospitalização; a atenção as suas necessidades de forma particular, considerando que cada criança possui diferentes necessidades de afeto e de sensibilidade à separação e à dor. Sendo assim, todas as iniciativas relativas à humanização da assistência hospitalar, poderão cooperar de maneira significante para a minimização dos traumas gerados dessa experiência, e ainda favorecerá o vínculo entre a equipe de saúde, a criança e sua família. ${ }^{4}$

Principalmente em Pediatria, o enfermeiro deve saber que, no ambiente hospitalar, a criança perde suas referências por estar longe de casa e de tudo que é comum em suas rotinas diárias, e que o hospital gera medo e restrições, devido ao seu quadro clínico. Avaliando que a criança exige maior atenção e cuidados, e que qualquer desestruturação em sua faixa etária intervém na qualidade de vida e em seu pleno desenvolvimento, aponta-se que a inclusão das atividades lúdicas no processo de cuidar em Enfermagem Pediátrica pode contribuir na diminuição dos efeitos estressores da hospitalização e transformar a assistência prestada consideravelmente mais humanizada. $^{7}$

As implicações da internação para a criança podem estar relacionadas a diferentes aspectos: a idade no momento da internação, tempo de hospitalização, tipo de afecção, orientações que obteve para a hospitalização, contatos terapêuticos anteriores, durante e posteriores a permanência no hospital. É relevante ainda observar a situação sócia 
econômica da família, o modo como está organizada, a convivência prévia com a criança, a maneira como costuma lidar com a ansiedade, os meios que lhe são ofertados para enfrentar o agravo e a internação. ${ }^{8}$

Zannon ao estudar o desenvolvimento psicológico da criança, ressalva a importância das pesquisas sobre a relação entre ambiente e organismo. Em especial, aponta que as pessoas apresentam respostas diante do desconhecido não só em decorrência das circunstâncias ou do processo de amadurecimento, mas pela combinação de um conjunto de oportunidades físicas e sociais há estímulos que são familiares ou não. Especificamente, no processo de hospitalização, muitas crianças vivem a necessidade de adaptarem-se a um ambiente desconhecido. Nessa visão, a criança passa a conviver com novas regras, recebe ordens para continuar num local determinado, veste roupas da instituição e vivencia relações com a equipe de saúde que provocam sentimentos e pensamentos variados. ${ }^{9}$

A humanização interliga o cuidar a diversos fatores, sendo primordial nesse período, e valoriza sentimento, cultura e realidade, possibilitando um envolvimento maior entre o profissional e a criança, em todas as dimensões. A atividade lúdica promove fatores significativos para o desenvolvimento psicomotor, cognitivo, social e afetivo da criança, proporcionando um tratamento humanizado. ${ }^{10}$
Alguns estudos demonstram o lúdico como uma medida terapêutica, que promove a continuidade do desenvolvimento infantil e possibilita o restabelecimento físico e emocional, por tornar a hospitalização menos traumatizante. O brincar diminui a tensão, a raiva, a frustração, o conflito e a ansiedade, e funciona como atividade-meio entre a criança e o profissional, pois facilita atingir os objetivos antes estabelecidos. $^{7}$

O brincar emerge como uma tentativa de transformar o ambiente hospitalar, em que proporciona condições para minimizar os danos psicológicos advindos do "hospitalismo", facilitando o acesso à atividade simbólica e a elaboração psíquica de vivências do cotidiano. Mediante os jogos simbólicos, a realidade externa pode ser assimilada à realidade interna, neste caso específico, auxiliando a criança hospitalizada a elaborar melhor esse momento. ${ }^{10}$

Neste contexto, a brincadeira além de ser uma maneira de enfrentamento da condição de internação, é uma ótima forma de humanizar as relações na situação de hospitalização. Com a criação da Lei $n^{\circ}$ 11.104, de 21 de março de 2005 pode-se constatar a relevância do brincar no ambiente hospitalar. A Lei relata a obrigatoriedade de criação de brinquedotecas nas unidades de saúde que prestem atendimento pediátrico em situação de internação. Segundo o Art. $2^{\circ}$ trata-se de brinquedoteca, para os efeitos desta Lei, o lugar munido de brinquedos e 
jogos educativos, designados a instigar as crianças e seus acompanhantes a brincar. Mas, para que o brincar seja realmente praticado e alcance suas finalidades no espaço hospitalar, é essencial que toda a equipe compreenda o significado do brincar para a criança. $^{5}$

A vivência de um espaço dedicado ao brincar dentro de um hospital mostra a preocupação com o bem-estar global da criança, proporcionando maior confiança nos pacientes e em seus familiares. Contribui também para a desmistificação do ambiente hospitalar, frequentemente percebido como hostil, uma vez que a possibilidade de brincar no hospital permitiria a visão desse ambiente como bom e agradável. Quando as pessoas vivenciam a hospitalização, a qualidade do ambiente pode afetar diretamente no processo da sua recuperação. Sendo assim, as intervenções no contexto hospitalar devem visar à promoção de condições favoráveis à reabilitação dos efeitos de experiências adversas ao desenvolvimento das crianças. O ambiente deve incentivar a saúde e deve ser organizado de maneira que atenda melhor às necessidades das crianças, considerando-se os aspectos psicológicos, pedagógicos e sociológicos da criança e de sua família. ${ }^{7}$

No início do estágio houve um pouco de dificuldade em relação à interação com a equipe de enfermagem da pediatria, o primeiro contato foi bem difícil. Também sentimos certa dificuldade na realização de alguns procedimentos, sentimos a ausência dos docentes para nos instruir ou mesmo para nos mostrarem outras formas de realizá-los, pois, na maioria das vezes, aquele procedimento ainda não tinha saído do livro ou dos bonecos de monitoria.

O que contribuiu bastante e nos ajudou durante o estágio, que é ressaltado por nós discentes, foi a cooperação e compreensão das mães e/ou acompanhantes das crianças, pois mesmo as crianças passando por vários especialistas e, muitas vezes, realizados os mesmos procedimentos, elas nunca se negavam e sempre colaboravam conosco e mesmo diante de todo sofrimento, nos tratavam com carinho e respeito.

Cabe ressaltar também a importância dos ensinamentos repassados pelas enfermeiras, pois, sempre que possível, elas se prestavam e nos ensinavam a colocarmos em prática nossa teoria, sendo assim, tivemos a oportunidade de realizar procedimentos e ações de enfermagem, não só com acompanhamento e supervisão, mas também com ensinamentos e interligação da teoria com a prática.

Como pontos negativos podemos citar os diferentes modos de cada enfermeira repassar as técnicas que eram empregadas em alguns procedimentos; a não solicitude de alguns profissionais em retirar nossas dúvidas e nos dar oportunidade de realizar procedimentos; o pouco tempo de permanência no setor, pois quando estávamos 
conseguindo confiança da equipe e da enfermeira plantonista tínhamos que ir para outro setor e a pouca destreza em realizar alguns procedimentos devido ao público ser infantil, que muitas vezes apresentavam recusa quando íamos realizar os mínimos procedimentos.

Já como pontos positivos, destacamos a disponibilidade de alguns profissionais, mesmo que muito pouco, em nos ensinar e tirar nossas dúvidas, além disso, também adquirimos mais conhecimento, tanto através da observação como da realização de algum procedimento; a oportunidade de conhecer mais de perto a realidade da pediatria; oportunidade de realizar alguns procedimentos; conquista da confiança demonstrada pela enfermeira.

Quanto ao que poderia ser oferecido para melhoria do serviço na unidade ressaltamos que as paredes das enfermarias deveriam ser coloridas, com pinturas de desenhos animados e outros enfeites, pois sabemos que um ambiente colorido contribui para diminuição da ansiedade e dos momentos estressantes em que as crianças passam durante sua permanência no hospital, pois é em um quarto de hospital que a criança passa a maior parte do seu dia. Por isso esse quarto deveria ser uma extensão da sua casa.

Outro aspecto bastante importante de ressaltar é que as enfermarias são muito quentes, com dificuldade de circulação de ar, deixando assim tanto as crianças como as mães e/ou acompanhantes estressadas, e algumas vezes, havia pequenos conflitos entre a equipe com as mães e/ou acompanhantes, pois elas (mães e/ou acompanhantes) se negavam a vestir as roupas que o setor dispõe para sua identificação. A instituição deveria procurar uma forma de tornar esses ambientes mais arejados para maior conforto $\mathrm{e}$ comodidade daquelas que se encontram neste ambiente. Além disso, poder-se-ia promover o aproveitamento e aprimoramento profissional e científico através da ética e da postura adequadas, favorecendo a integração interprofissional.

Manter um atendimento mais humanizado com essas crianças é primordial, compreendendo os momentos em que essas famílias enfrentam. Humanizar é também investir em melhorias nas condições de trabalho dos profissionais da área, é alcançar benefícios para a saúde e qualidade de vida dos usuários, dos profissionais e da comunidade.

\section{CONSIDERAÇÕES FINAIS}

Verificou-se a importância da utilização do lúdico na prática diária, pelos profissionais da saúde, facilitando a assistência à criança hospitalizada. Observamos que a promoção do brincar na hospitalização infantil pode facilitar, abrindo possibilidades para uma assistência mais criativa e humanizada, reduzindo os efeitos estressantes. Na tentativa de alcançar a 
humanização na assistência à criança no processo de doença, a equipe de profissionais de saúde dispõe de instrumento capaz de proporcionar vivências com novos objetos, sensações, atividades e sentimentos não ameaçadores. Desta forma, as ações humanizadas proporcionam a dinâmica de interações sendo sua utilização a articulação entre o tratamento e cura da criança hospitalizada.

A criança enfrenta dificuldades com as experiências dolorosas e desagradáveis, portanto, o apoio daqueles que assistem a criança é essencial para a adaptação no âmbito hospitalar e tratamentos aos quais é submetida, pois a atuação diferenciada com a criança contribui no cotidiano da internação. Com isso, cabe salientar que a tríade profissional -brinquedo - criança interliga propósitos e expectativas, facilitando a interação positiva, sendo o brinquedo predominantemente a ferramenta relevante à intervenção humanizada, promovendo o movimento entre mundo real e imaginário transpondo as barreiras do adoecimento. Assim, faz-se necessário o envolvimento no processo terapêutico, minimizando a angústia da criança e familiares, priorizando o universo infantil, maximizando o potencial de afetividade, amor e vontade de ser companheiro da criança na experiência vivenciada.

Durante o Estágio Supervisionado de Enfermagem II, percebemos que tanto o
Hospital Universitário Alcides Carneiro HUAC como a equipe de enfermagem da Pediatria acreditam na real importância de incentivarem o brincar das crianças ali internas, bem como contribuem positivamente neste cuidar. A brinquedoteca do HUAC é repleta de brinquedos, jogos, pinturas, atividades recreativas, músicas especificamente para crianças e, contempla também, profissionais específicos para desenvolverem o lúdico. Além da brinquedoteca, encontramos grupos e/ou projetos que incentivam ainda mais o brincar, bem como ajudam a diminuir o estresse desencadeado pela internação das crianças, o que tem contribuído muito na evolução positiva delas.

\section{REFERÊNCIAS}

1.CARLO, M. M. R. P.; QUEIROZ, M. E. Dor e cuidados paliativos - Terapia Ocupacional e Interdisciplinariedade. São Paulo: Rocca, 2009. Disponível em: <http: //tocoletiva.com.br/wpcontent/uploads/2012/0 2/TCC_A_TO_e_o_brincar_na_enfermariape diatrica.pdf >. Acessado em 18 fev. 2014.

2. CRUZ, D. S. M. Humanização da assistência de enfermagem - relato de caso sobre o uso do brinquedo terapêutico. Rev. Ciênc. Saúde Nova Esperança,v. 11, no 3, p. 47-53. Disponível em: $<$ http://www.facene.com.br/wpcontent/upload s/2010/11/6Humaniza\%C3\%A7\%C3\%A3o_d a_assist \%C3\%AAncia-deenfermagem_editado.pdf $>$. Acessado em 18 fev. 2014.

3.DUARTE, M. L. C.; NORO, A. HUMANIZAÇÃO: uma leitura a partir da 
compreensão dos profissionais da enfermagem. Rev Gaúcha Enfermagem, v. 31, n. 4, p. 685-92. Porto Alegre (RS), 2010. Disponível em: < http://www.scielo.br/pdf/rgenf/v31n4/a11v31 n4.pdf>. Acesso em: 09/02/2014.

4.FAQUINELLO, P. et al. o Atendimento humanizado em unidade pediátrica: percepção do Acompanhante da criança hospitalizada. Texto Contexto Enfermagem, v. 16, n. 4, p. 609-616. Disponível em: <http://www.scielo.br/pdf/tce/v16n4/a04v16n 4.pdf >. Acessado em: 09/02/2014

5.FROTA, M. A. et al. O lúdico como instrumento facilitador na humanização do cuidado de crianças hospitalizadas.

CogitareEnferm; v 12 n. 1, p 69-75, 2007 jan/mar. Disponível em:

<http://ojs.c3sl.ufpr.br/ojs2/index.php/cogitar e/article/view/8270/5781>. Acessado em:

08/02/2014.

6.LIMA, F. E. T.; JORGE, M. S. B.; MOREIRA, T. M. M.Humanização hospitalar: satisfação dos profissionais de um hospital pediátrico. Rev. bras.

enferm. [online]. 2006, vol.59, n.3, pp. 291296. ISSN 0034-7167. Disponível em: < http://www.scielo.br/scielo.php?pid=S0034$71672006000300008 \&$ script=sci_arttext $>$ Acessado em: 09/02/2014.

7.OLIVEIRA, L. D. B. et al. A brinquedoteca hospitalar como fator de promoção no desenvolvimento infantil: relato de experiência. Revista brasileira de crescimento e desenvolvimento humano, v. 19, n. 2, p. 306-312, 2009. Disponível em: http://pepsic.bvsalud.org/scielo.php?pid=S01 0412822009000200011\&script=sci_arttext\&tl ng=es>. Acessado em: 08/02/2014.

8.MOREIRA, D. S. et al. . As práticas lúdicas no cotidiano do cuidar em enfermagem pediátrica. Esc Anna Nery Rev Enferm; v.13 n. 4, p. 802-08, 2009 out-dez.Disponível em: <http://www.scielo.br/pdf/ean/v13n4/v13 n4a16.pdf $>$. Acessado em 10 fev. 2014.
9.SILVA, S. H. et al. Humanização em pediatria: o brinquedo como recurso na assistência de enfermagem à criança hospitalizada. Pediatr. mod [Internet], v. 46, n. 3, p. 101-4, 2010. Disponível em: <http://www.moreirajr.com.br/revistas.asp ?id_materia $=4353 \&$ fase $=$ imprime $>$. Acessado em: 08/02/2014.

10.MENEZES, M.; MORE, C. L. O. e CRUZ, R. M. O desenho como instrumento de medida de processos psicológicos em crianças hospitalizadas. Aval. psicol. [online] vol.7, n.2, pp. 189-198. ISSN 2175-3431, 2008. Disponível em: $<$ http://pepsic.bvsalud.org/pdf/avp/v7n2/v7n2 a10.pdf $>$. Acessado em 10 fev. 2014. 